\title{
Prevalência de casos de tricomoníase em laudos citopatológicos de um laboratório particular da cidade do Crato - Ceará
}

\author{
Prevalence of tricomoníase cases in citopatological reports of a particular laboratory of \\ the city of Crato-Ceará
}

\author{
Monaiza de Oliveira Lima ${ }^{1}$, Mariana Gomes Vidal Sampaio ${ }^{2 *}$ \\ ${ }^{1}$ Graduada em Biomedicina pelo Centro Universitário Dr. Leão Sampaio.; \\ ${ }^{2}$ Mestre em Biotecnologia Industrial pela UFPE - Centro Universitário Católica Quixadá.
}

\begin{abstract}
Resumo
Objetivo: o presente artigo tem como objetivo avaliar a prevalência de mulheres infectadas pelo protozoário Trichomonas vaginalis ( $T$. vaginalis) em um laboratório particular da cidade do Crato, Ceará. Metodologia: tratou-se de um estudo do tipo descritivo, retrospectivo com abordagem quantitativa. A coleta de dados foi realizada em um Laboratório particular de Análises Clínicas, localizado na cidade de Crato-CE, cujo grupo de estudo foi todas as mulheres, com idade entre 17 e 87 anos, que realizaram o exame de Papanicolau no período de 2014 a 2016. Resultados: foram quantificados os percentuais de amostras positivas para a tricomoníase e outras patologias correlatas obtendo-se como resultado que entre os anos de 2014 a 2016 foram realizados 28.910 exames citopatológicos, dos quais $2,22 \%$ foram positivos para tricomoníase. Dentre os casos positivos $22,15 \%$ apresentaram co-infecção com outros microrganismos, sendo a Gardnerella vaginalis a principal bactéria encontrada, obtendo um total de $80,99 \%$ dos casos, Cândida sp com $11,97 \%$ dos casos, Leptothrix com 5,63\% e Papilomavírus humano (HPV) com 1,41\% dos casos. Observou-se que a faixa etária com maior incidência de tricomoníase é entre 26 a 45 anos, com um percentual de $65,21 \%$, sendo possível notar a alta prevalência de tricomoníase na população feminina. Conclusão: os resultados foram apresentados a Secretaria de Saúde da cidade de Crato - Ceará com o intuito de alertar os profissionais de saúde com relação ao número de casos, incentivando a periodicidade do exame de Papanicolau e outros exames voltados ao diagnóstico dessa patologia, além de uma atenção especial ao tratamento das mulheres já infectadas. Palavras chaves: IST. Teste de papanicolau. Trichomonas vaginalis.
\end{abstract}

\begin{abstract}
Objective: the present article aims to evaluate the prevalence of women infected by the protozoan Trichomonas vaginalis (T. vaginalis) in a private laboratory in the city of Crato, Ceará. Methodology: this was a descriptive, retrospective study with a quantitative approach. The data collection was performed in a Private Laboratory of Clinical Analyzes, located in the city of Crato-CE, whose study group were all women aged between 17 and 87 years who underwent the papanicolau in the period from 2014 to 2016. Results: the percentages of positive samples for trichomoniasis and other related pathologies were quantified, resulting in 28.910 cytopathological exams between 2014 and 2016, of which 2.22\% were positive for trichomoniasis. Among the positive cases, 22.15\% presented co-infection with other microorganisms, Gardnerella vaginalis being the main bacterium found, obtaining a total of $80.99 \%$ of the cases, Candida sp. With $11.97 \%$ of the cases, Leptothrix with 5, 63\% and human papillomavirus (HPV) with $1.41 \%$ of the cases. It was observed that the age group with the highest incidence of trichomoniasis is between 26 and 45 years old, with a percentage of $65.21 \%$, being possible to note the high prevalence of trichomoniasis in the female population. In view of these results it is possible to note the high prevalence of trichomoniasis in the female population. Conclusion: the results were presented to the Health Department of the city of Crato-Ceará with the aim of alerting health professionals about the number of cases, encouraging the periodicity of the papanicolau and other tests aimed at the diagnosis of this pathology, besides paying special attention to the treatment of women already infected.

Keywords: IST. Papanicolau Test. Trichomonas vaginalis.
\end{abstract}

\section{INTRODUÇÃO}

O protozoário flagelado Trichomonas vaginalis é o agente etiológico da tricomoníase, doença Infecciosa Sexualmente Transmissível não viral mais comum em todo o mundo, podendo ser assintomática em alguns casos e, em outros pode levar a severa vaginite nas mulheres (MACIEL; TASCA; DE CARLI, 2004).

Correspondente/ Corresponding: *Mariana Gomes Vidal Sampaio End.: Rua Antônio Gonçalves sobreira 1081 Tiradentes / Juazeiro do Norte-Tel: (88) 98801-2441 -E-mail: marianavidalsampaio@gmail.com
Os homens na grande maioria são portadores assintomáticos deste parasita. Quando sintomáticos podem manifestar disúria, corrimento uretral de aspecto purulento, infecção do epidídimo e próstata e dor testicular (COUTO, 2015). Nas mulheres o odor fétido e dispareunia são relatados em alguns casos, podendo ocasionar cervicite, uretrite, secreção purulenta, espumosa, amarelo esverdeada, prurido, disúria, colpitis macularis ou colo em morango (DOMEIKA et al., 2010; LIMA et al., 2013; PESSOA et al., 2012).

T. vaginalis pode sobreviver até uma semana no prepúcio do homem, e assim sua transmissão pode ocorrer 
para a mulher, o homem acaba sendo um veiculador da infecção, já que se trata de uma doença de transmissão sexual (BRAVO et al., 2010).

Para a colonização do trato geniturinário, o pH precisa estar alcalino, tendo desta forma uma decaída dos Lactobacillus, favorecendo assim o crescimento do $T$. vaginalis. Este protozoário causa um processo inflamatório, ocasionando destruição de alguns leucócitos por fagocitose (LEHKER; ALDERETE, 2000).

Um dos problemas que pode ser ocasionado por essa patologia durante a gravidez é a vulvovaginite, esta pode evoluir para complicações gestacionais mais graves, como: parto prematuro, rotura prematura da membrana e corioamnionite (NUNES; FRANÇA; TRAEBET, 2018).

Para a prevenção contra essa doença recomenda-se a utilização de preservativos durantes as relações sexuais, diminuir a quantidade de parceiros sexuais, tomar cuidado com o uso de fômites e evitar o uso dos mesmos ou esterilizá-los (HOBBS et al., 2006).

Devido a estas complicações se faz importante à realização de pesquisas que demonstrem a incidência da doença na população, pois os casos de tricomoníase não são de notificação compulsória no Brasil. Com a estimativa de casos os profissionais da saúde poderão tomar medidas cabíveis para o controle e erradicação desta patologia, alcançando de forma efetiva a promoção e prevenção em saúde. $\mathrm{O}$ objetivo do presente estudo foi avaliar a prevalência de mulheres infectadas pelo protozoário Trichomonas vaginalis em um laboratório particular da cidade do Crato, Ceará.

\section{METODOLOGIA}

\section{TIPO DE ESTUDO}

Tratou-se de um estudo do tipo descritivo, retrospectivo com abordagem quantitativa.

LOCAL

Os dados para realização do estudo foram coletados em um Laboratório particular de Análises Clínicas, localizada na cidade de Crato-CE.

\section{POPULAÇÃO E AMOSTRA}

O grupo de estudo são todas as mulheres, com idade entre 17 a 87 anos, que realizaram o exame de Papanicolau entre os anos de 2014 a 2016 em um laboratório particular na cidade de Crato-Ceará. Com os laudos citopatológicos foi quantificado o percentual de amostras positivas para a tricomoníase e outras patologias correlatas.

\section{PROCESSO DE OBTENÇÃO DE DADOS E VARIÁVEIS}

Os dados dos exames foram obtidos através do software Shift LIS ${ }^{\circledR}$, que é o sistema adotado pelo laboratório em questão, onde foram analisados e diferenciados os seguintes parâmetros: idade, os casos positivos para a tricomoníase e associação com outros tipos de infecções, tais como: Gardnerella vaginalis, Candida sp., Leptothrix e papilomavírus humano (HPV).

\section{TABULAÇÃO E FORMA DE APRESENTAÇÃO DOS DADOS}

Foram elaborados gráficos e tabelas com todos os dados referentes à pesquisa, com o auxílio do software Microsoft Excel ${ }^{\circledast}$, versão 2010, onde foi empregada a comparação dos dados com outras literaturas semelhantes.

\section{ASPECTOS ÉTICOS}

O presente trabalho foi aprovado pelo comitê de ética em pesquisa do Centro Universitário Leão Sampaio - UNILEÃO, com o número do comprovante 105909/2017.

\section{RESULTADOS}

Entre os anos de 2014 e 2016 foram realizados 28.910 exames citopatológicos, dos quais 641 (2,22\%) foram positivos para tricomoníase.

A Tabela 1 mostra a quantidade de exames de Papanicolau realizados nos anos de 2014 a 2016 e a quantidade de exames positivos para infecção por T.vaginali. $O$ ano com maior percentual de casos positivos foi o de 2014, com um percentual de $3,15 \%$ (367), enquanto que o menor número de casos foi detectado no ano de 2015, com um percentual de $0,86 \%$ (98).

Tabela 1 - Quantitativo de exames citopatológicos realizados entre os anos de 2014 a 2016 em um laboratório particular na cidade de Crato, Ceará.

\begin{tabular}{lcc}
\hline & Total de exames realizados & Exames positivos \\
\hline 2014 & 11.651 & $367(3,15 \%)$ \\
2015 & 11.460 & $98(0,86 \%)$ \\
2016 & 5.799 & $176(3,04 \%)$ \\
Total: & 28.910 & $641(2,22 \%)$ \\
\hline
\end{tabular}

Fonte: Autoria própria.

Foram quantificados os casos positivos para tricomoníase, bem como aqueles com associação a outros microrganismos além do parasita T. vaginalis. Na Tabela 2 estão relatados os casos de tricomoníase associados a outros tipos de infecção.

Tabela 2 - Correlação entre T. vaginalis e infecção com outros microrganismos.

\begin{tabular}{lcc}
\hline & T. vaginalis & $\begin{array}{c}\text { T. vaginalis associado a outra } \\
\text { infecção }\end{array}$ \\
\hline 2014 & 367 & $106(28,88 \%)$ \\
2015 & 98 & $11(11,22 \%)$ \\
2016 & 176 & $25(14,20 \%)$ \\
Total: & 641 & $142(22,15 \%)$ \\
\hline
\end{tabular}

Fonte: Autoria própria.

Os microrganismo encontrados em associação com $T$. vaginalis foram a Gardnerella vaginalis com 115 (80,99\%) 
casos, Cândida sp com 17 (11,97\%) casos segundo mais prevalente, Leptothrix com 8 casos (5,63\%) e Papilomavírus humano (HPV) com 2 (1,41\%) casos. Na Figura 1 estão expostos em percentual os microrganismos encontrados em associação com T.vaginali.

Figura 1 - Tipos de microrganismo associados à infecção por T. vaginalis.



Fonte: Autoria própria

A Figura 2 mostra a quantidade de casos da infecção por T. vaginalis por faixa etária. Sendo a mais prevalente a faixa etária entre 26 a 45 anos, correspondendo a 418 casos (65,21\%). Entre 17 a 25 anos corresponderam a 99 casos (15,44\%), 46 a 60 anos 108 casos (16,85\%) e muIheres com mais de 61 anos representaram (2,50\%) casos.

Figura 2 - Percentual de casos de Trichomonas vaginalis por faixa etária.

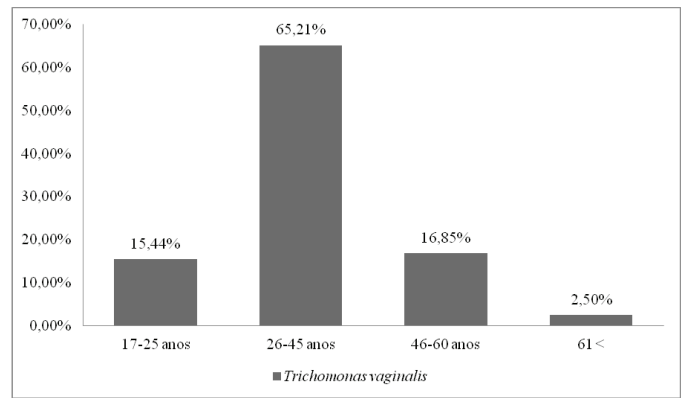

Fonte: Autoria própria

\section{DISCUSSÃO}

Os resultados obtidos a partir dos 28.910 laudos coletados foram que os casos positivos para tricomoníase corresponderam a 2,22\% do total de laudos. Na literatura existem diversos trabalhos com resultados similares ao deste.

Véras et al. (2019) realizou um trabalho com uma amostragem de 2.642 testes de Papanicolau, onde foram confirmados $2 \%$ de casos de infecção por $T$. vaginalis. Desta forma o resultado é semelhante ao do presente artigo, onde se obteve um percentual de $2,22 \%$.

Um estudo realizado por Couto (2015) no município de Teixeira, Paraíba demonstrou que 2,95\% das mulheres apresentaram exame positivo para tricomoníase. Outra pesquisa, feita com 288 mulheres da cidade de Chaves, Portugal, detectou a incidência do protozoário em 3,8\% das mulheres estudadas e apenas $54,5 \%$ eram sintomáticas o restante não relatou nenhuma sintomatologia (ALVES et al., 2011). Neste trabalho o percentual de mulheres infectadas por essa parasitose foi de $2,22 \%$, corroborando assim com os estudos acima citados.

Em alta Sorocabana - São Paulo no ano de 2012 foi realizado um estudo com um total de 26.699 Exames dos quais $143(0,54 \%)$ foram positivos para a parasitose, já no Estado de São Paulo foram realizados 2.611 .876 exames e 16.536 mulheres $(0,63 \%)$ tiveram positividade (DAN et al., 2013).

Mosca e Mendonça (2016) analisaram 4.934 laudos ginecológicos de Unidades Básicas de Saúde, na cidade de Mandaguari, destes, 2,9\% foram positivos para o microrganismo T.vaginali. Resultado semelhante ao que foi obtido com esta pesquisa.

Exames citopatológicos realizados no Laboratório de análises clínicas da Pontifícia Universidade Católica de Goiás, no ano de 2013, mostrou positividade para T.vaginali com um percentual de 1,6\% (CHAN; RIBEIRO, 2018).

O parasita sexualmente transmissível $T$. vaginalis pode ser encontrado isoladamente causando a infecção ou pode vir acompanhado de outros microrganismos. Existem alguns que são encontrados com mais frequência em associação ao $T$ vaginali. Neste artigo foram encontrados alguns microrganismos causando infecção juntamente com o parasita estudado.

Durante a colonização do trato geniturinário pelo $T$. vaginalis, o pH acaba alcalinizando, tendo desta forma uma decaída dos Lactobacillus, favorecendo assim o seu crescimento (LEHKER; ALDERETE, 2000). A Gardnerella vaginalis ocasiona a vaginose bacteriana, crescendo e proliferando-se em pH alcalino (RAUGUST; DUARTE, 2013), isto pode explicar o fato desta bactéria ser o microrganismo mais prevalente em associação a tricomoníase.

Um estudo realizado com 1.344 gestantes mostrou o percentual de infecção com dois ou mais microrganismo patogênico foi de 3,05\%, onde T. vaginalis e Gardnerella vaginalis representou 10,52\% (2) e T. vaginalis e Cândida sp. 26,31\% (5) (BONFANTI; GONÇALVES, 2010). Cavalcante et al.(2005) fizeram um trabalho com 145 mulheres, onde o percentual obtido de casos de Cândida sp. associado a $T$. vaginalis foi de $1,2 \%$. Tais estudos destoam deste, pois neste artigo percentual de T. vaginalis e Gardnerella vaginalis foi o maior (80,99\%), e de Cândida sp. e T. vaginalis foi o segundo maior (11,97\%).

O Leptothrix é uma bactéria filamentosa que é considerada um marcador para a possível presença de $T$. vaginalis (LONGATTO FILHO; SILVA FILHO, 2000), no entanto neste trabalho a quantidade de co-infecção por Leptothrix foi mínima, sendo a co-infecção por Gardnerella vaginalis a mais prevalente, discordando assim da literatura existente.

A tricomoníase é uma doença que pode acometer as mulheres em diversas faixas etárias, no entanto existem certas idades onde a incidência é bem maior. Os dados que 
foram coletados possuem as idades das pacientes, onde foram quantificados mais casos da infecção entre as idades de 26 á 45 anos, com um percentual de 65,21\%.

O resultado deste trabalho é semelhante ao de Zorati e Mello (2009) onde mostrou uma maior incidência entre 20 á 49 anos. Segundo alguns autores esta faixa etária corresponde à fase reprodutiva da mulher, onde a mesma está exposta a mudanças do ciclo menstrual, gravidez e possui uma vida sexual mais ativa (SUTCLIFFE et al., 2010).

Foram coletados em Cascavel e na região oeste do estado do Paraná um total de 211.940 exames, deste, 3.752 foi positivo, no estado a faixa etária com maior incidência foi entre 40 a 44 anos, já em Cascavel e região Oeste foi entre 45 a 49 anos (ZORATI; MELO, 2009).

Ter mais de 20 anos de idade é considerado um fator de risco para a infecção por $T$. vaginalis segundo Helms et al. (2008), onde em seu estudo essa faixa etária foi a mais acometida, obtendo um percentual de $13 \%$ de mulheres com infecção prevalente.

\section{CONCLUSÃO}

Conclui-se que a incidência de tricomoníase em muIheres atendidas em um laboratório particular da cidade de Crato - Ceará é de 2,22\% (641), do total de 28.910 exames citopatológicos analisados no período de 2014 a 2016. Sendo a faixa etária mais acometida de 26 a 45 anos, podendo ser explicada por ser a fase sexual mais ativa da mulher. O microrganismo mais prevalente em co-infecção por $T$. vaginali foi Gardnerella vaginalis, tendo um percentual de $80,99 \%$ (115) em relação aos outros microrganismos, no entanto a bactéria Leptothrix que é citada em algumas literaturas como o microrganismo indicador da presença do parasita T.vaginali, teve um percentual inferior de 5,63\%.

Diante destes resultados é possível notar a alta prevalência de tricomoníase na população feminina, o que é bastante preocupante, pois se trata de uma IST capaz de provocar graves manifestações clínicas.

Os resultados foram apresentados a Secretaria de Saúde da cidade de Crato - Ceará com o intuito de alertar os profissionais de saúde com relação ao número de casos, incentivando a periodicidade do exame de Papanicolau e outros exames voltados ao diagnóstico dessa patologia, além de uma atenção especial ao tratamento das mulheres já infectadas.

\section{REFERÊNCIAS}

ALVES, M. J. et al., Epidemiologia de Trichomonas vaginali em mulheres. Rev. Port. Saúde Pública, Lisboa, v. 29, n. 1, p. 27-34, 2011.

BONFANTI, G.; GONÇALVES, T. L. Prevalência de Gardnerella vaginalis, Candida spp e Trichomonas vaginali em exames citopatológicos de gestantes atendidas no hospital universitário de Santa Maria-RS. Rev. saúde, Santa Maria, v. 36, n. 1, p. 37-46, jan./jun. 2010.

BRAVO, R. S. et al. Tricomoníase vaginal: o que se passa?. DST-J. bras. Doenças Sex. Transm., Rio de Janeiro, v. 22, n. 2, p. 73-80, 2010.

CAVALCANTE, V. L.N. et al. Rastreamento de candidose vaginal durante a prevenção do câncer cérvico - uterino. DST - J. Bras. Doenças Sex.
Transm., Rio de Janeiro, v. 17, n. 1, p. 44-48, 2005.

CHAN, S. A. C.; RIBEIRO, A. A. Prevalência dos agentes microbiológicos estratificados por faixa etária no laboratório de análises clínicas da Pontifícia Universidade Católica de Goiás. Rev. Estudo Vida e Saúde PUC, Goiás, v. 45, p. 80-86, 2018.

COUTO, V. L. Epidemiologia da Tricomoníase na população humana masculina e feminina, do município de Teixeira, Paraíba/ Brasil. 2015. Dissertação [Licenciatura em Ciências Biológicas] - Universidade Federal de Campina Grande, Patos, 2015.

DAN, V.J. L et al. Prevalência de tricomoníase na alta Sorocabana e no estado de São Paulo. Rev. Colloquium Vitae, São Paulo, v. 5, n. 1, p. 3039, jan./jun. 2013.

DOMEIKA, M. et al. Guidelines for the laboratory diagnosis of trichomoniasis in East European countries. J. Eur. Acad. Dermatol. Venereol., Malden,v. 24, p. 1125-1134, 2010.

LONGATTO FILHO, A. ; SILVA FILHO, A. de M. E. Colo uterino e vagina processos inflamatórios. Rio de Janeiro: Revinver, 2000.

HELMS, D. J. et al. Fatores de risco para Trichomonas vaginali prevalentes e incidentes entre mulheres atendidas três clínicas de doenças sexualmente transmissíveis. Sex. Transm. Dis., Filadélfia, v. 35, n. 5, p. 484-485, maio 2008.

HOBBS, M. M. et al. Methods for detection of Trichomonas vaginali in the male partners of infected women: implications for control of trichomoniasis. J. Clin. Microbiol., Washington, v. 44, n. 11, p. 3994-3999, Nov. 2006.

LEHKER, M. W.; ALDERETE, J. F. Biology of trichomonosis. Curr. Opin. Infect. Dis., London, v. 13, n. 1, p. 37-45, Feb. 2000.

LIMA, M. C. L. et al. Prevalência e fatores de risco independentes à tricomoníase em mulheres assistidas na atenção básica. Acta paul. enferm., São Paulo, v. 26, n. 4, p. 331-337, 2013.

MACIEL, G.P; TASCA, T; DE CARLI, G. A. Aspectos clínicos, patogênese e diagnóstico de Trihomonas vaginalli.. J. Bras. Patol. Med. Lab., Rio de Janeiro, v. 40, n. 3, p. 152-160, jun. 2004.

MOSCA, V. A. B.; MENDONÇA, P. S. B. Tricomoníase e outras vulvovaginites em mulheres atendidas em unidades básicas de Saúde de Mandaguari. Rev. UNINGÁ, Maringá, v. 28, n. 2, p. 47-51, 2016.

NUNES, R. D.; FRANÇA, C. L.; TRAEBET, J. L. Prevalência de vulvovaginites na gestação e sua associação com complicações perinatais. Arq. Catarin. Med., Santa Catarina, v. 47, n. 1, p. 121-132, 2018.

PESSOA, D. C. et al. Trichomonas vaginali: como agente casual de cérvico -colpite. Infarma - Ciênc. farm, Brasília, v. 24, n. 1-3, p. 124-131, 2012.

RAUGUST, T. M.; DUARTE, A. C. R. Aspectos clínicos, epidemiológicos e diagnóstico citológico de Cândida sp., Gardnerella vaginalis e Trichomonas vaginali. Atas de Ciênc. Saúde, São Paulo, v. 1, n. 1, 2013.

SUTCLIFFE, S. et al. Prevalence and correlates of Trichomonas vaginali infection among females US federal prisioninmates. Sex. Transm. Dis., Filadélfia, v. 37, p. 585-590, 2010.

VÉRAS, G. C. B. et al. Análise dos resultados do teste de Papanicolau entre usuários da atenção primária: estudo transversal. Enferm. Foco, Brasília, v. 10, n. 1, p. 29-33, 2019.

ZORATI, G. C.; MELLO, S. A. Incidência da tricomoníase em mulheres atendidas pelo sistema único de saúde em Cascavel e no Oeste do Paraná. Arq. Ciênc. Saúde, Umuarama, v. 13, n. 2, p. 133-138, maio/ago. 2009.

Submetido em: 25/04/2019

Aceito em: 04/07/2019 